\section{A REPORT \\ on}

\section{THE BILIARY SECRETION OF THE DOG: WITH REFERENCE TO THE ACTION OF CHOLAGOGUES: \\ Presented to the Scientific Grants Committee of the British Medical Association.*}

By W I L L I A M R U T H E R F O R D, M.D., F.R.S., Professor of the Institutes of Medicine in the University of Edinburgh; ASSISTED BY

M. VIGNAL AND WM. J. DODDS, M.B., D.Sc.

\section{SUMMARY OF RESULTS.}

\section{First SERIES.}

I. In a curarised dog that has fasted eighteen hours, the secretion of bile is tolerably uniform during the first four or five hours after the commencement of the experiment, but falls slightly as a longer period elapses. Its composition remains constant.

2. Croton-oil is a hepatic stimulant of very feeble power. The high place assigned to it by Röhrig was probably the result of his imperfect method of experiment.

3. Podophyllin is a very powerful stimulant of the liver. During the increased secretion of bile, the percentage amount of the special bile solids is not diminished. If the dose be too large, the secretion of bile is not increased. It is a powerful intestinal irritant.

4. Aloes is a powerful hepatic stimulant. It renders the bile more watery, but at the same time increases the excretion of biliary matter by the liver.

5. Rhubarb is a certain, though not a powerful, hepatic stimulant. The bile secreted under its influence has the normal composition.

6. Senna is a hepatic stimulant of very feeble power. It renders the bile more watery.

7. Colchicum increases to a considerable extent the amount of biliary matter excreted by the liver, although it renders the bile more watery.

8. Taraxacum is a very feeble hepatic stimulant.

9. Scammony is a very feeble hepatic stimulant.

Io. Gamboge is an intestinal, but not a hepatic, stimulant.

I I. Castor-oil stimulates the intestinal glands, but not the liver.

I2. Calomel stimulates the intestinal glands, but not the liver.

Second Series.

13. Euonymin is a powerful hepatic stimulant. It is not nearly so powerful an irritant of the intestine as podophyllin.

14. Sanguinarin is a powerful hepatic stimulant. It also stimulates the intestine, but not nearly so powerfully as podophyllin.

15. Iridin is a powerful hepatic stimulant. It also stimulates the intestine, but not so powerfully as podophyllin.

16. Leptandria is a hepatic stimulant of moderate power. It is a feeble intestinal stimulant.

17. Ipecacuan is a powerful hepatic stimulant. It increases slightly the secretion of intestinal mucus ; but has no other apparent stimulant effect on the intestine. The bile secreted under the influence of ipecacuan has the normal composition.

18. Colocynth is a powerful hepatic as well as intestinal stimulant. It renders the bile more watery, but increases the secretion of biliary matter.

19. Jalap is a powerful hepatic as well as intestinal stimulant.

20. Sodium-sulphate is a hepatic stimulant of considerable power.

It also stimulates the intestinal glands.

21. Magnesium-sulphate is an intestinal but not a hepatic stimulant.

22. Potassium-sulphate is a hepatic and intestinal stimulant of considerable power. Its action on the liver is, however, uncertain, probably owing to its sparing solubility.

23. Sodium-phosphate is a powerful hepatic, and a moderately powerful intestinal stimulant. lant.

24. Rochelle salt is a feeble hepatic but a powerful intestinal stimu-

25. Ammonium-chloride stimulates the intestinal glands, but not the liver.

26. Dilute nitrohydrochloric acid is a hepatic stimulant of considerable power.
27. Mercuric chloride (corrosive sublimate) is a powerful hepatic stimulant, while it is a feeble intestinal stimulant. Although calomel is an intestinal but not a hepatic stimulant, excitement of the liver as well as of the intestinal glands results when mercuric chloride and calomel are administered together.

\section{THIRD SERIES.}

28. Calabar bean stimulates the liver, but not powerfully, unless it be given in very large doses.

29. Atropia-sulphate antagonises the effect of Calabar bean on the liver, and thereby reduces the hypersecretion of bile produced by that substance. It does not, however, arrest the secretion of bile, and, when given alone, does not notably affect it.

30. Menispermin does not stimulate the liver. It slightly stimulates the intestinal glands.

3r. Baptisin is a hepatic and also an intestinal stimulant of considerable power.

32. Phytolaccin is a hepatic stimulant of considerable power. It also slightly stimulates the intestinal glands.

33. Acetate of lead, in large doses, somewhat diminishes the secretion of bile, probably by a direct action on the liver.

34. Ammonium-phosphate is a moderately powerful stimulant of the

liver. It does not stimulate the intestinal glands.

35. Tannic acid does not affect the secretion of bile.

36. Hydrastin is a moderately powerful hepatic stimulant, and a feeble intestinal stimulant.

37. Juglandin is a moderately powerful hepatic and a mild intestinal stimulant.

38. Sodium-benzoate is a powerful hepatic stimulant. It is not an intestinal stimulant.

39. Ammonium-benzoate stimulates the liver, but not quite so powerfully as the sodium-salt of benzoic acid. It does not stimulate the intestinal glands.

40. Benzoic acid stimulates the liver, but, owing to its insolubility, its action is less rapid and much less powerful than that of its alkaline salts.

4I. Sodium-salicylate is a very powerful hepatic stimulant. It does not notably stimulate the intestinal glands.

42. Sodium-chloride is a very feeble hepatic stimulant.

43. Sodium-bicarbonate has scarcely any appreciable effect as a hepatic stimulant, even when given in very large doses.

44. Potassium-bicarbonate feebly excites the liver, and that only when given in very large doses.

45. Potassium-iodide has no notable effect on the biliary secretion

46. Sulphate of manganese does not excite the liver, though it is a powerful excitant of the intestinal glands.

47. Morphia has no appreciable effect on the secretion of bile, and does not prevent the stimulating effect of such a substance as sodium. salicylate.

48. Hyoscyamus does not notably affect the biliary secretion, and does not interfere with the stimulating effect of such a substance as sodium-salicylate.

49. Pure diluted alcohol does not affect the biliary secretion.

50. Jaborandi is a very feeble hepatic stimulant.

All the above conclusions are based on experiments performed on the dog, and have no reference to any observations made on the human subject.

Table 7 affords an approximative indication of the comparative powers of the chief hepatic stimulants as indicated by the hourly coefficients of secretion per kilogramme of the dog's body-weight. Part of the table was published at the close of the second series; but it will be serviceable to reproduce that part, to readily compare its results with those obtained in the concluding experiments.

As already explained, the coefficients of bile-secretion under the influence of hepatic stimulants (Table 7), cannot be regarded as an absolute index of relative powers of the stimulants, even in the case of the dog ; because, in some instances-e.g., those of aloes, podophyllin, and physostigma - the doses were excessive. It would be unfair to compare the effects of such doses with those of moderate doses of other substances. And, as has also been previously stated, young dogs secrete, in proportion to their size, more bile than old dogs; therefore, a higher coefficient is the rule in their case. We have, as far as possible, taken these points into consideration, and the summary of results above given contains the conclusions at which we have arrived.

\section{Results of Experiments with Iridin and Euonymin on MAN.}

Although we must leave to our medical brethren the task of testing on the human subject the effects of baptisin, sanguinarin, phytolaccin, hydrastin, juglandin, etc., it will doubtless be of service if we here re- 
TABLE VII.

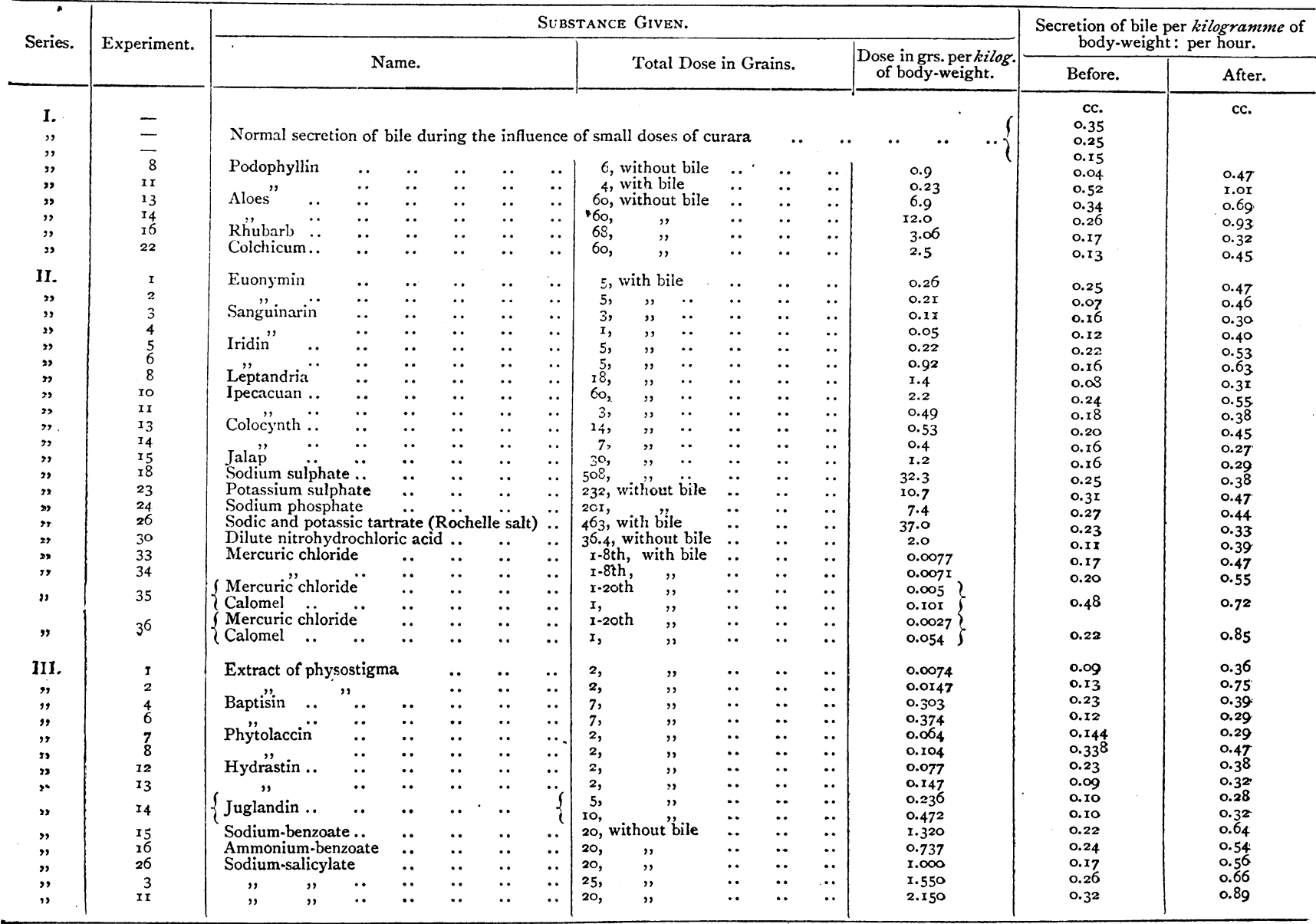

count our experience of the use of iridin and eunymin. As yet, we have found four grains of iridin-made into a pill with confection of roses, and taken at bedtime-a certain remedy for biliousness. It produces no disagreeable sensations, and, on awaking in the morning, the yellow tongue is found to be clean, and the headache and malaise gone. As iridin, though a powerful hepatic, is not a powerful intestinal stimulant, it is well to give in the morning an ordinary mild saline aperient, such as Püllna water or some other. But iridin, though an agreeable remedy at the time, leaves a somewhat depressed effect; and it probably should not be taken oftener than once a week or so. Euonymin is a hepatic stimulant in man, as it is in the dog. Two grains of itmade into a pill with confection of roses, and taken at night, seem to be as efficient a remedy for biliousness as iridin. If the dose be not too great, it leaves no depression. As it is a feeble intestinal stimulant, it is well to follow it in the morning by a dose of Puillna water or other saline aperient. I have been much struck with the success of euonymin, in functional hepatic derangement, in several persons who had tried nearly all the commonly used cholagogues with varying and often very limited success. I have no doubt that, in consequence of our experiments, euonymin will come to be an universally employed hepatic stimulant.*

\section{Mode of Action of Hepatic Stimulants.}

But although we have definitely proved that a large number of substances stimulate the liver to secrete more bile, we do not profess to have absolutely shown in what manner they do this. It may be asked-

I. Do they excite the mucous membrane of the duodenum or other part of the small intestine, and thereby induce reflex excitement of the liver? One would be readily disposed to entertain this idea from the

* Euonymin, iridin, sanguinarin, etc., may be obtained from Mr. Squire, Oxford Street, London, and from Messrs. Duncan, Flockhart, and Co., Princes Street,
Edinburgh. fact that stimulation of the oral mucous membrane so readily induce secretion in the salivary glands; yet we are obliged to reject the idea that this likewise holds true of the liver, because such substances as gamboge and magnesium-sulphate powerfully irritate the intestinal mucous membrane, but do not in the least increase the secretion of bile. On the other hand, such - substances as ipecacuan, sodium- and ammonium-benzoate, powerfully excite the liver without inducing any notable excitement of the intestine.

2. Do these substances stimulate the hepatic cells by merely increasing the stream of blood through the liver? Whatever be the state of the hepatic vessels during increase of the biliary secretion, it is quite certain that increased secretion of bile does not necessarily follow dilatation of the intestinal capillaries; the effect of which, if it be not.carried to excess, may with reason be supposed to increase the stream of blood through the portal vein and thence through the liver. But castor-oir greatly dilates the intestinal capillaries, yet the bile-secretion does not rise in the least.

3. We therefore believe that the effect of hepatic stimulants is to be assigned to a direct action of their molecules upon the hepatic cells or their nerves. The effect of physostigma and atropia rather points to an action on the latter-in their instance, at all events-as has been already indicated (BRITISH Medical Journal, December 21st, 1878). But we do not think it advisable at present to pursue this difficult subject, which, as far as we can see, is of little importance compared with knowing what does and what does not stimulate the liver.

It is particularly to be observed that all our experiments concern the influence of substances on the bile-secreting mechanism. The nature of our method has forbidden any observations on the action of drugs on the bile-expelling mechanism. Seeing that the acid chyme, by irritating the duodenal mucous membrane, effects a reflex expulsion of bile, it may be that many substances which stimulate the duodenum have a similar effect. Yet we cannot but think that to bring about an expulsion of bile by muscular contraction of the gall-bladder and bile-ducts 
is, in all probability, a small thing when compared with increasing the secretion of bile. One might expect that such powerful intestinal irritants as magnesium-sulphate and gamboge would be likely to bring about a reflex expulsion of bile; yet no one has attributed any cholagogue power to these. But, without attempting to reason out a question that can only be determined by experiment, we would merely add that we leave the investigation of the action of drugs on the bile-expelling mechanism to those who care to enter upon such an inquiry. We are satisfied to have shown that every substance supposed to be a cholagogue has, with the exception of calomel and manganese-sulphate, the power of exciting the bile-secreting mechanism; and, as our estimate of their powers, from an observation of the bile-secretion only, closely agrees with observations on the human subject, where actions on the bile-secreting and on the bile-expelling mechanisms cannot be distinguished from one another, we cannot but infer that surely their actions on the human subject must be chiefly on the bile-secreting mechanism. With regard to calomel, we must refer the reader to our criticism of its action at the close of the second series of experiments (JouRNAL, 1877), and we have already commented upon manganese-sulphate (p. 107).

The term cholagogue is of necessity a vague one, and is applicable to any substance that increases the biliary flow, whether by augmenting the secretion of bile or by exciting contraction in the gall-bladder and bile-ducts. We have, therefore, applied the more definite term hepatic stimulant to those substances which we have proved to increase the secretion of bile.

[To be continued.]

\section{AN ADDRESS}

ON

\section{THE WORK OF THE BRITISH MEDICAL ASSOCIATION.}

Deliverd at the Second Annual Meeting of the Dublin Branch.

BYY GEORGE H. PORTER, M.D., F.R.C.S.I., Surgeon in Ordinary to the Queen in Ireland; President of the Branch.

Gentlemen,-Twelve months have now rolled over since you entrusted to my charge the high responsibility which, to-day, I am about to give back into your hands-that of President of this most important and influential Branch of the British Medical Association. Twelve months! A long period to which to look forward; yet how short the retrospect! During that time not much has occurred, so far as the peculiar interests of this Branch are concerned, to require special notice from me. Indeed, were such events alone to be considered, I might dismiss them with but few observations; yet this Branch, unit as it is of one great integer, has suffered a severe loss-has much to deplore-in the removal from our midst, in the meridian of his usefulness, of the late President of the British Medical Association. I need scarcely add I allude to Dr. Eason Wilkinson. That a gentleman occupying such a position amongst us should have strong claims upon our respect, and that his unexpected death, occurring just at the period it did, should give our community a severe shock, seems only natural. But in his case, the memory of Dr. Wilkinson has a stronger demand upon our sympathies than would under ordinary circumstances arise, and for this reason. A year ago, an important era arose in the history of the British Medical Association-the first meeting of the Dublin Branch was held. Its inauguration was signalised by an eloquent and exhaustive address, the memory of which, doubtless, still fills your recollections, and the assemblage was graced by the attendance of that kind, good old gentleman, the President of the parent Association, braving, at an inclement season of the year, the "désagrements" of the sea. He came amongst us, and cast over our meeting the prestige of his high official position, and shed upon it the light of his genial presence. That was the first occasion, I believe, that many of us had ever met him, yet I venture to assert that his conduct and bearing at the meeting impressed us most favourably; and, as the result, when his unexpected death was announced, I think myself justified in stating, that probably there was not one member of this Branch who did not feel that in the President's death he had, to a certain extent, suffered a personal bereavement.

If there be truth in the phrase that "non cuivis homini contingit adire Corinthum", what a much greater amount of truth is there not to be found in the statement that it is permitted but to few indeed amongst us to make startling discoveries in medical or surgical science, whereby long accepted practice is revolutionised, and new points of departure started!

How few of us could ever hope to rival such original thinkers as were Harvey, Jenner, Hunter? Yet there is not one in our ranks who may not fulfil an useful rôle in his own sphere, by upholding a high standard of professional honour, and of moral integrity; acting in such a manner as to command the respect of the public at large, and thereby elevating in their estimation the profession to which he belongs.

Such a man was Dr. Eason Wilkinson. His character may well be estimated from that address which he had prepared for the late meeting of the Association at Bath, but which he was not spared to deliver, and from which I ask your permission to read a few extracts, supporting the views I have just enunciated. He had written :-

"I should like to say a few words upon the future of our profession. Its portals are being narrowed year by year, and it will come to pass that only men who have arrived at a very high standard of knowledge will be allowed to enter them. I look forward to this and other causes for the immeasurable raising of our social position. The hindrances to our advancement are indifference, private interests-which engender pitiable jealousies-too great intentness upon 'getting on', and making money. All this, instead of a gallant esprit de corps, and steadfast pride in raising and upholding our grand profession. We have all heard it said, some of us often, and by our inferiors possibly in birth and education-'He's only a doctor'. Only a doctor! Now, let us see what that means. It means a costly and, though very interesting, yet a very anxious and laborious education; it means, in all who are worthy of the profession, enormous self-denial, earnest thought, truthfulness, integrity, purity of life, sympathy with human suffering, unceasing labour, obedience to God's Word.

"It seems to me, then, to be a 'doctor' in the world's acceptation of the word, means to be a man worthy of the highest possible love and esteem of all with whom he may come in contact. Let us, therefore, encourage our sons to adopt this profession, to have high aims and noble aspirations. We must endeavour to influence all to look upwards and onwards in the highest sense; that is, in the hope of being an honour to his calling and a blessing to his generation, and not in damaging aims at self-aggrandisement."

Ample evidence on the part of 'sorrowing friends, at the meeting in question, was brought forward to sustain the fact that, as he spoke, so he lived. In my opinion, higher praise could nat be accorded to any man.

Passing from this sad theme, gentlemen, permit me to occupy your attention for a short time whilst I bring under your notice some of the principal objects for the advancement of which this Association was originally founded, and which, from its birth up to the present moment, its members have steadily kept in view. These may, with advantage, be grouped under the following headings:-

I. The scientific culture of our profession :

2. The consideration of questions of what may be termed medicopolitical reform :

3. State Medicine :

4. Though last, by no means least, the development of social intercourse amongst the vast body of our profession through the instrumentality of our great annual gathering, and the meetings of the several Branches into which the Association itself has been subdivided.

With reference to the first of these groups, it is scarcely necessary for me to remind you how thoroughly this intention of the founders of the Association has been carried out at our several annual meetings. The addresses delivered by the Presidents of the different Sections in which the work of the meeting is conducted, taken one and all, are highly creditable to their authors, most of whom have been the foremost men in our ranks. In Medicine, Surgery, Midwifery, and State Medicine, addresses, from time to time, have been delivered, which will remain classics in our literature, and which would be well worthy of collection and republication. That this will yet be done, I doubt not, inasmuch as it would be matter for regret that essays of such importance should not occupy a more permanent position in our professional writings than can as yet be claimed for them. But it is not only at our annual meetings that such good work is achieved; reference to the pages of our JOURNAL will show that, on many occasions, most valuable communications are made by members at the meetings of the Branch Associations-contributions which otherwise might be lost to our profession.

It is true that, in large cities, such as London, Dublin, and Edinburgh, no like requirement exists. In this city, every opportunity is afforded by important bodies as the Surgical, the Medical, the Obstetrical, the Pathological, and the Biological Societies; but in other 